\title{
ARTIKEL PENELITIAN PENGARUH TEKNIK RELAKSASI BERNAFAS TERHADAP KEMAJUAN PERSALINAN PRIMIGRAVIDA INPARTU
}

\author{
Nyna Puspita Ningrum \\ Prodi DIII Kebidanan, Universitas PGRI Adi Buana Surabaya \\ Email : nyna_oliviano@yahoo.com
}

\begin{abstract}
ABSTRAK
Rasa nyeri persalinan dapat mempengaruhi kontraksi uterus melalui sekresi kadar katekolamia dan kartisol yang menaikkan dan akibatnya mempengaruhi durasi persalinan menjadi lama atau memanjang. Relaksasi merupakan proses mengistirahatkan tubuh dan pikiran dari segala beban fisik dan kejiwaan, sehingga ibu menjadi lebih tenang dalam menghadapi proses persalinan dan membuat proses kontraksi berlangsung aman, alami, dan lancar.

Tujuan umum penelitian ini adalah untuk mengetahui pengaruh teknik relaksasi bernafas terhadap kemajuan persalinan pada primigravida inpartu kala I. Desain penelitian ini bersifat analitik dengan pendekatan cross sectional dan dihitung menggunakan metode Chi Square. Sampel penelitian merupakan 42 ibu hamil trimester III di BPM Enny Juniati pada bulan Agustus - September 2015.

Setelah dilakukan uji analisa data dengan menggunakan metode Chi-square test, diketahui $x^{2}$ tabel : 3,841 dan besaran $x^{2}$ hitung : 6,109; diperoleh hasil $x^{2}$ hitung $>x^{2}$ tabel. Berdasarkan penelitian ini diketahui responden yang kemajuan persalinan sesuai yakni 15 responden (35.71\%) dengan diajarkan teknik relaksasi bernafas, 7 responden (16.67\%) dengan tidak diajarkan teknik relaksasi bernafas. Sedangkan yang tidak sesuai kemajuan persalinannya sebanyak 6 responden (14.29\%) dengan diajarkan teknik relaksasi bernafas dan 14 responden (33.33\%) dengan tidak diajarkan teknik relaksasi bernafas. Maka dapat disimpulkan bahwa "ada pengaruh teknik relaksasi bernafas terhadap kemajuan persalinan pada primigravida kala I di BPM Enny Juniati Surabaya".

Dari hasil penelitian ini diharapkan kepada petugas kesehatan agar terus berupaya melaksanakan penyuluhan bagaimana cara mengatur nafas serta memberikan pendampingan. Sedangkan bagi ibu hamil dianjurkan untuk melatih teknik relaksasi bernafas dapat digunakan karena mudah dan tidak membutuhkan biaya.
\end{abstract}

Kata Kunci : pernafasan, relaksasi, kemajuan persalinan

\section{PENDAHULUAN}

Hamil dan melahirkan adalah anugerah yang luar biasa bagi wanita, tetapi ibu hamil sering dihinggapi rasa takut dan cemas akan bayangan proses melahirkan yang sulit dan menyakitkan (nyeri). Rasa nyeri pada persalinan dalam hal ini adalah nyeri kontraksi uterus yang dapat mengakibatkan peningkatan aktivitas sistem saraf simpatis, peruabahan tekanan darah, denyut jantung, pernafasan dengan warna kulit dan apabila tidak segera diatasi maka akan meningkatkan rasa khawatir, tegang, takut dan stress (Bobak, 2004). Nyeri persalinan dapat mempengaruhi kontraksi uterus melalui sekresi kadar katekolamia dan kartisol yang menaikkan dan akibatnya mempengaruhi durasi persalinan.
Nyeri juga dapat menyebabkan aktivitas uterus yang tidak terkoordinasi yang akan mengakibatkan persalinan lama. (Varney, 2008).

Ketenangan ibu menjadi kunci penting saat proses persalinan. Seorang ibu hamil bisa saja melahirkan tanpa rasa sakit, atau dengan rasa sakit yang minimal. Salah satu cara yang dapat dilakukan adalah dengan melakukan teknik relaksasi. Angka kematian ibu masih cukup tinggi yaitu 307 per 100.000 kelahiran hidup. Sekitar $70 \%$ kematian maternal disebabkan oleh tekanan darah tinggi, 15\% karena aborsi tidak aman, dan $15 \%$ karena persalinan lama. Persalinan lama salah satunya disebabkan karena power atau kekuatan ibu yang kurang efektif. Oleh karena itu 
ibu membutuhkan relaksasi sehingga kebutuhan oksigen terpenuhi dan ibu memiliki cukup tenaga. Relaksasi merupakan proses mengistirahatkan tubuh dan pikiran dari segala beban fisik dan kejiwaan, sehingga ibu menjadi lebih tenang dalam menghadapi proses persalinan. Relaksasi juga membuat sirkulasi darah rahim, plasenta, dan janin menjadi lancar sehingga kebutuhan oksigen dan makanan sijanin terpenuhi. Sirkulasi darah yang lancar juga akan membuat otot-otot yang berhubungan dengan kandungan dan janin seperti otot panggul, punggug, dan perut menjadi rileks dan kendur. Sementara ketika persalinan, relaksasi membuat proses kontraksi berlangsung aman, alami, dan lancar (Maryati, 2010).

Berdasarkan data yang diperoleh dari salah satu RS di Jakarta menunjukkan $48 \%$ ibu bersalin melakukan relaksasi sehingga mereka dapat beradaptasi dengan rasa sakit yang muncul saat persalinan. Menurut studi pendahuluan yang di lakukan di BPM Enny Juniati Surabaya menunjukkan jumlah persalinan sebanyak 22 pada bulan Mei 2015, ibu yang kurang benar dalam melakukan relaksasi sebanyak 13 (59\%) dan yang benar-benar melakukan relaksasi sebanyak 9 (41\%). Ternyata ibu yang melakukan tehnik relaksasi dengan benar dapat mengatasi rasa sakit yang berlebihan saat persalinan, sehingga ibu sangat kooperatif, tidak terjadi perpanjangan kala I, dan ibu memiliki tenaga (power) yang cukup untuk menjalani proses persalinannya dengan lancar,. Persalinan dapat berjalan lancar juga dipengaruhi oleh beberapa faktor yaitu, passage (jalan lahir), passenger, penolong, dan psikologi dari ibu. (Sondakh, 2013) Mengurangi rasa sakit dapat dilakukan dengan salah satu cara diantaranya adalah teknik relaksasi dan pernafasan. Adapun relaksasi bernafas selama proses persalinan dapat mempertahankan komponen system syaraf simpatis dalam keadaan homeostatis sehingga tidak terjadi peningkatan suplai darah, mengurangi kecemasan dan ketakutan ibu agar ibu dapat beradaptasi dengan proses persalinan. Semakin meningkat jumlah persalinan,maka tanggung jawab tenaga kesehatan ditempat-tempat pelayanan kesehatan semakin berat. Khususnya bagaimana melaksanakan metode yang dapat membantu mengatasi masalah yang muncul saat proses persalinan Dengan melakukan teknik relaksasi bernafas akan membantu ibu dalam menghemat tenaga dan mengurangi keletihan, menenangkan pikiran dan mengurangi rasa sakit sehingga proses persalinan berjalan lancar. Penelitian ini bertujuan untuk mengetahui seberapa besar teknik relaksasi bernafas dapat mempengaruhi kemajuan persalinan pada primigravida inpartu kala I.

\section{KAJIAN LITERATUR PENGEMBANGAN HIPOTESIS}

DAN

Relaksasi adalah seni melepaskan ketegangan otot yang merupakan kunci dari kenyamanan selama persalinan (Simkin dkk, 2007).Teknik relaksasi dapat mengurangi sensasi nyeri dan mengontrol intensitas reaksi ibu terhadap rasa nyeri (Henderson, Jones, 2005). Relaksasi Pernapasan adalah membebaskan pikiran dan beban dari ketegangan yang dengan sengaja diupayakakan dan dipraktekkan Relaksasi sadar telah ditemukan berkaitan dengan penurunan ketegangan otot dan menurunkan laju metabolisme. Relaksasi sadar terhadap seluruh tubuh selama persalinan tampak meningkatkan keefektifan kontraksi uterus. Ketika dikombinasikan dengan pernapasan, relaksasi dapat membantu ibu bersalin mengatasi nyeri lebih efektif pada setiap kontraksi dan istirahat lebih penuh di antara kontraksi.

Teknik relaksasi bernafas merupakan tindakan pengendalian nyeri non farmakologis yang dapat membantu ibu mengendurkan seluruh tubuhnya kektika rahim berkontraksi. Beberapa jenis pernafasan bisa membantu ibu dalam menghadapi persalinan kala I (Sebelum diperbolehkan mengedan) antara lain :

a. Menarik nafas dalam (untuk membantu ibu rileks) dilakukan pada awal akhir kontraksi.

b. Menarik nafas dangkal dan cepat di dada bagian atas, dilakukan pada saat kontraksi mencapai puncaknya.

c. Menarik nafas pendek dan cepat diikuti dengan menghembuskan nafas melalui mulut dan dilakukan untuk menahan keinginan untuk mengedan (sebelum terjadi pembukaan lengkap).

Pada tahap ini, teknik pernafasan dapat memperbaiki relaksasi otot-otot abdomen dan dengan demikian meningkatkan ukuran rongga abdomen. Keadaaan ini mengurangi friksi (gesekan) dan rasa tidak nyaman antara rahim dan dinding abdomen karena otot-otot di daerah genitalia juga menjadi lebih rileks, otot-otot tersebut tidak mengganggu penurunan janin. Pada tahap II, ibu mulai boleh mengedan dan diselingi dengan manarik nafas cepat dan pendek. Pada tahap ini, pernafasan dipakai untuk menaikkan 
tekanan abdomen dan dengan demikian membantu mengeluarkan janin. Keadaan ini juga dipakai untuk merelaksasikan otot-otot fundamental untuk mencegah pengeluaran dini kepala janin.

Persalinan adalah suatu proses membuka dan menipisnya serviks dan janin turun ke dalam jalan lahir. Kelahiran adalah prose dimana janin dan ketuban didorong keluar melalui jalan lahir (Sarwono, 2008). Persalinan adalah proses pengeluaran (kelahiran) hasil konsepsi yang dapat hidup diluar uterus melalui jalan lahir (Sondakh, 2013).

Faktor-faktor yang yang mempengaruhi proses persalinan antara lain :

a. Jalan lahir (passage)

Keadaan panggul merupakan faktor penting dalam kelangsungan persalinan, tetapi yang tidak kurang penting adalah hubungan antara kepala janin dengan panggul ibu. Besarnya kepala janin dalam perbandingan dengan luasnya panggul ibu menentukkan apakah ada disproporsi sefalopelvik atau tidak.

b. Penumpang (passager)

Penumpang dalam persalinan adalah janin dan plasenta. Hal-hal yang perlu diperhatikan adalah ukuran kepala janin, presentasi,letak, sikap, dan posisi janin; sedangkan yang perlu diperhatikan pada plasenta adalah letak, besar, dan luas.

c. Tenaga atau kekuatan (power)

Faktor kekuatan dalam persalinan dibagi atas dua, yaitu :

1. Kekuatan primer dari segmen atas uterus yang menebal dan dihantarkan ke uterus bawah dalam bentuk gelombang. Kekuatan primer ini mengakibatkan serviks menipis (affacement) dan berdilatasi sehingga janin turun.

2. Kekuatan sekunder, pada kekuatan ini otot-otot diafragma dan abdomen ibu berkontraksi dan mendorong keluar isi (janin dan plasenta) kejalan lahir sehingga menimbulkan tekanan intraabdomen.

d. Posisi ibu (Positioning)

Posisi ibu dapat mempengaruhi adaptasi anatomi dan fisiologi persalinan. Perubahan posisi yang diberikan pada ibu bertujuan untuk menghilangkan rasa letih, memberi rasa nyaman, dan memperbaiki sirkulasi.

e. Respon Psikologi (Psychology Response) Respon psikologi ibu dapat dipengaruhi oleh:
1. Dukungan ayah bayi/ pasangan selama proses persalinan

2. Dukungan kakek-nenek (saudara dekat) selama persalinan

3. Saudara kandung bayi selama persalinan

\section{METODE PENELITIAN}

Desain penelitian ini adalah analitik karena metode penelitian yang dilakukan dengan tujuan utama menganalisa pengaruh teknik relaksasi bernafas terhadap kemajuan persalinan dengan pendekatan cross sectional (Notoatmodjo, 2012). Populasi dalam penelitian ini adalah seluruh ibu bersalin primigravida kala 1 di BPM Enny Juniati Surabaya periode bulan Agustus September 2015. Instrument yang digunakan pada penelitian ini adalah observasi dan lembar partograf. Setelah data terkumpul maka akan dilakukan analisa data dan diuji dengan menggunakan Uji Chi Square.

Dimana,

$$
x^{2}=\sum \frac{(f o-f h)^{2}}{f h}
$$

$\mathrm{x}^{2}=$ chi kuadrat

fo $=$ frekuensi yang diperoleh berdasarkan data

$\mathrm{fh}=$ frekuensi yang diharapkan

\section{HASIL DAN PEMBAHASAN}

Data umum berupa karakteristik ibu bersalin yang meliputi umur ibu, tinggi badan ibu, berat badan ibu, ukuran lingkaran lengan atas (lila), ukuran tinggi fundus uteri (TFU), fase kepala janin sudah memasuki pintu atas panggul (PAP), dan tafsiran berat janin (TBJ). Dapat dilihat pada tabel sebagai berikut :

\begin{tabular}{cccc}
\hline No & Umur & n & \% \\
\hline $\mathbf{1}$ & $20-25$ tahun & 19 & 45.24 \\
$\mathbf{2}$ & $26-30$ tahun & 21 & 50.00 \\
$\mathbf{3}$ & $>30$ tahun & 2 & 4.76 \\
\hline Jumlah & & 42 & 100.00 \\
\hline
\end{tabular}

Tabel 4.1 - Distribusi Berdasarkan Umur

Pada penyajian tabel diatas menunjukkan bahwa berdasarkan umur responden, umur 20 25 tahun sebanyak 19 responden (45.24\%). 
Responden berumur 26 - 30 tahun sebanyak 21 responden $(50.00 \%)$, dan responden umur $>30$ tahun sebanyak 2 responden $(4.76 \%)$.

\begin{tabular}{cccc}
\hline No & Tinggi Badan & n & \% \\
\hline $\mathbf{1}$ & $150-155 \mathrm{~cm}$ & 21 & 50.00 \\
$\mathbf{2}$ & $156-160 \mathrm{~cm}$ & 18 & 42.86 \\
$\mathbf{3}$ & $>160 \mathrm{~cm}$ & 3 & 7.14 \\
\hline Jumlah & & 42 & 100.00 \\
\hline Tabel 4 2 - Distribusi Berdasarkan Tinggi
\end{tabular}

Pada penyajian tabel diatas menunjukkan bahwa berdasarkan tinggi badan responden, tinggi badan 150 - 155 tahun sebanyak 21 responden $(50.00 \%)$. Responden bertinggi badan 156 - 160 tahun sebanyak 18 responden $(42.86 \%)$, dan responden dengan tinggi badan > 160 tahun sebanyak 3 responden $(7.14 \%)$.

\begin{tabular}{cccc}
\hline No & Berat Badan & N & \% \\
\hline $\mathbf{1}$ & $55-65 \mathrm{~kg}$ & 7 & 16.67 \\
$\mathbf{2}$ & $66-75 \mathrm{~kg}$ & 26 & 61.90 \\
$\mathbf{3}$ & $>75 \mathrm{~kg}$ & 9 & 21.43 \\
\hline Jumlah & & 42 & 100.00
\end{tabular}

Tabel 4.3 - Distribusi Berdasarkan Berat Badan

Berdasarkan tabel diatas responden yang memiliki berat badan rentang 55 - $65 \mathrm{~kg}$ sebanyak 7 responden (16.67\%), responden dengan berat badan rentang $66-75 \mathrm{~kg}$ sebanyak 26 responden (61.90\%), sedangkan respon dengan berat badan lebih dari $75 \mathrm{~kg}$ sebanyak 9 responden $(21.43 \%)$.

\begin{tabular}{cccc}
\hline No & $\begin{array}{c}\text { Lingkar } \\
\text { Lengan Atas }\end{array}$ & N & \% \\
\hline $\mathbf{1}$ & $<23.5 \mathrm{~cm}$ & 0 & 0.00 \\
$\mathbf{2}$ & $>23.5 \mathrm{~cm}$ & 42 & 100.00 \\
\hline Jumlah & & 42 & 100.00 \\
\hline
\end{tabular}

Tabel 4.4 - Distribusi Berdasarkan Lingkar Lengan Atas

Pada penyajian tabel diatas menunjukkan bahwa berdasarkan ukuran lingkar lengan atas, responden, seluruh sampel (42 responden, 100\%) dengan ukuran lebih dari $23.5 \mathrm{~cm}$.

\begin{tabular}{|c|c|c|c|}
\hline No & $\begin{array}{c}\text { Tinggi Fundus } \\
\text { Uteri }\end{array}$ & $\mathbf{N}$ & $\%$ \\
\hline 1 & $25-30 \mathrm{~cm}$ & 38 & 90.48 \\
\hline 2 & $>30 \mathrm{~cm}$ & 4 & 9.52 \\
\hline Jumlah & & 42 & 100.00 \\
\hline
\end{tabular}

Berdasarkan tabel diatas karakteristik responden berdasarkan ukuran tinggi fundus uteri, responden dengan tinggi fundus uteri antara 25 $30 \mathrm{~cm}$ sebanyak 38 responden $(90.48 \%)$, dan dengan ukuran tinggi fundus uteri lebih dari 30 cm sebanyak 4 responden $(9.52 \%)$.

\begin{tabular}{cccc}
\hline No & $\begin{array}{c}\text { Kepala Janin Memasuki } \\
\text { Pintu Atas Panggul }\end{array}$ & N & \% \\
\hline $\mathbf{1}$ & Belum Memasuki PAP & 9 & 21.43 \\
$\mathbf{2}$ & Sudah Memasuki PAP & 33 & 78.57 \\
\hline Jumlah & & 42 & 100.00 \\
\hline Tabel 4.6 - Distribusi Berdasarkan Fase Kepala \\
Janin Memasuki Pintu Atas Panggul
\end{tabular}

Berdasarkan tabel diatas karakteristik responden berdasarkan fase kepala janin memasuki pintu atas panggul, responden yang belum memasuki pintu atas panggul 9 responden $(21.43 \%)$, dan yang sudah sebanyak 33 responden $(78.57 \%)$.

\begin{tabular}{cccc}
\hline No & $\begin{array}{c}\text { Tafsiran Berat } \\
\text { Janin }\end{array}$ & n & \% \\
\hline $\mathbf{1}$ & $<2500 \mathrm{gr}$ & 15 & 35.71 \\
$\mathbf{2}$ & $>2500 \mathrm{gr}$ & 27 & 64.29 \\
\hline Jumlah & & 42 & 100.00 \\
\hline
\end{tabular}

Tabel 4.7 - Distribusi Berdasarkan Tafsiran Berat Janin

Tabel diatas menunjukkan berdasarkan tafsiran berat janin responden, 15 responden (35.71\%) kurang dari 2500 gram, dan yang lebih dari 2500 gram sebanyak 27 responden (64.29\%). 


\begin{tabular}{cccc}
\hline No & $\begin{array}{c}\text { Pelatihan Teknik } \\
\text { Relaksasi Bernafas }\end{array}$ & n & $\boldsymbol{\%}$ \\
\hline $\mathbf{1}$ & Tidak Diajarkan & 21 & 50.00 \\
$\mathbf{2}$ & Diajarkan & 21 & 50.00 \\
\hline Jumlah & & 42 & 100.00 \\
\hline
\end{tabular}

Tabel 4.8 - Distribusi Responden Pelatihan

Teknik Relaksasi Bernafas

Responden yang diikutkan pelatihan teknik relaksasi bernafas sebanyak 21 responden $(50.00 \%)$, dan yang tidak diikutkan pelatihan teknik relaksasi bernafas sebanyak 21 responden (50.00\%).

\begin{tabular}{cccc}
\hline No & Kemajuan Persalinan & & $\mathbf{\%}$ \\
\hline $\mathbf{1}$ & Tidak Sesuai & 20 & 47.62 \\
$\mathbf{2}$ & Sesuai & 22 & 52.38 \\
\hline Jumlah & & 42 & 100.00 \\
\hline
\end{tabular}

Tabel 4.9 - Distribusi Berdasarkan Kemajuan Persalinan

Berdasarkan kemajuan persalinan, responden yang tidak sesuai sebanyak 20 responden $(47.62 \%)$, dan yang sesuai 22 responden $(52.38 \%)$.

\begin{tabular}{|c|c|c|c|c|c|c|c|}
\hline No & $\begin{array}{c}\text { Kemajuan } \\
\text { Persalinan } \\
\text { Penerapan Teknik } \\
\text { RelaksasiBernafas }\end{array}$ & Sesuai & $\%$ & $\begin{array}{l}\text { Tidak } \\
\text { Sesuai }\end{array}$ & $\%$ & Jumlah & $(\%)$ \\
\hline 1 & Diajarkan & 15 & 35.71 & 6 & 14.29 & 21 & 50.00 \\
\hline \multirow[t]{2}{*}{2} & Tidak Diajarkan & 7 & 16.67 & 14 & 33.33 & 21 & 50.00 \\
\hline & Total & 22 & 52.38 & 20 & 47.62 & 30 & 100.00 \\
\hline
\end{tabular}

Tabel 4.10 - Tabulasi Silang "Pengaruh TeknikRelaksasi Bernafas Terhadap Kemajuan Persalinan

Berdasarkan tabel diatas, yang menunjukkan bahwa dari 42 responden dalam penelitian ini responden yang kemajuan persalinan sesuai yakni 15 responden $(35.71 \%)$ dengan diajarkan teknik relaksasi bernafas, 7 responden $(16.67 \%)$ dengan tidak diajarkan teknik relaksasi bernafas. Sedangkan resonden yang tidak sesuai kemajuan persalinannya sebanyak 6 responden $(14.29 \%)$ dengan diajarkan teknik relaksasi bernafas dan 14 responden $(33.33 \%)$ dengan tidak diajarkan teknik relaksasi bernafas.
Setelah dilakukan uji statistik pada tabulasi silang diatas dengan menggunakan metode Chi-square test, dengan berdasarkan $\mathrm{x}^{2}$ tabel : 3,841 dan besaran $\mathrm{x}^{2}$ hitung : 6,109; maka $\mathrm{x}^{2}$ hitung 6,109> $\mathrm{x}^{2}$ tabel 3.841. dengan demikian $\mathrm{H}_{1}$ diterima dan $\mathrm{H}_{0}$ ditolak yakni "ada pengaruh teknik relaksasi bernafas terhadap kemajuan persalinan pada primigravida kala I di BPM Enny Juniati Surabaya". 


\section{KESIMPULAN}

Berdasarkan landasan teori dan didukung oleh data yang diperoleh saat penelitian, maka dapat di simpulkan sebagai berikut :

a. Kemajuan persalinan pada primigravida inpartu kala I tanpa melakukan teknik relaksasi bernafas di BPM Enny Juniarti sebagian besar tidak sesuai atau memanjang dengan dimana 7 responsen kemajuan persalinan sesuai dan 14 responden kemajuan persalinan tidak sesuai.

b. Kemajuan persalinan pada primigravida inpartu kala I dengan melakukan teknik relaksasi bernafas di BPM Enny Juniarti sebagian besar sesuai atau tidak memanjang dengan 15 responsen keamajuan persalinan sesuai dan 6 responden kemajuan persalinan tidak sesuai).

c. Ada pengaruh teknik relaksasi bernafas terhadap kemajuan persalinan pada primigravida inpartu kala I setelah dilakukan uji dengan metode Chi-square test, dimana $\mathrm{x}^{2}$ tabel $=3.841<\mathrm{x}^{2}$ hitung $=$ 6.109 .

Dalam rangka turut menyumbangkan pemikiran yang berkenaan dengan melatih teknik relaksasi bernafas maka disarankan hal-hal sebagai berikut.

a. Bagi tenaga kesehatan

Perlu adanya peningkatan pelaksanaan teknik relaksasi pada ibu bersalin. Pengarahan atau penyuluhan dari petugas kesehatan kepada ibu hamil masih sangat diperlukan misalnya dengan penyuluhan bagaimana cara mengatur nafas. Selain itu pendampingan dari tenaga kesehatan sangat berperan dalam keberhasilan pelaksanaan teknik relaksasi ini.

b. Bagi pasien

Proses persalinan merupakan hal yang fisiologis bagi setiap wanita. Tetapi sebagian wanita merasa takut dan cemas karena rasa sakit yang muncul. Oleh karena itu teknik relaksasi bernafas dapat digunakan karena mudah dan tidak membutuhkan biaya. Sehingga ibu bersalin dapat beradaptasi dengan persalinannya.

c. Bagi Keluarga

Peran serta dan dukungan dari suami atau keluarga sangat diperlukan oleh ibu dalam menghadapi proses persalinan diharapkan suami atau keluarga dapat membantu ibu dalam pelaksanaan teknik relaksasi, misalnya dengan membantu ibu dalam mengatur nafas atau membantu merubah posisi. Hal ini dapat menyebabkan ibu bersalin menghemat tenaga sehingga proses persalinan berjalan lancar.

\section{REFERENSI}

Alimul, A. (2007). Metode Penelitian Kebidanan dan Teknik Analisis Data. Jakarta: Salemba Medika.

Anonimous (2008). Melahirkan Tanpa Rasa Sakit. http://www.hanyawanita.com.

(Diakses, 17 Pebruari 2012).

Enkin. (2010). Asuhan Sayang Ibu. Jakarta: Salemba Medika.

Evany, A. (2007). Melahirkan Tanpa Rasa Sakit. Jakarta : PT Bhuana Ilmu Populer.

Arikunto, S. (2002). Prosedur Penelitian Suatu Pendekatan Praktek. Jakarta: PT Rineke Cipta.

Bobak, Lowdermilk, Jensen. (2004). Buku ajar keperawatan maternitas. Alih bahasa: Maria A. Wijayarini, Peter I. Anugerah. Jakarta: EGC.

Danuatmadja, B. (2004). Persalinan Tanpa RasaSakit. Jakarta: Puspa Swara.

Depkes RI. (2012). Buku Acuan Persalinan Normal Bersih dan Aman. Jakarta : JNP-KR.

Henderson, J. (2005). Relaksasi dan Adaptasi Nyeri. Jakarta : Pustaka Sinar Harapan.

Jenny J. S. Sondakh. (2013). Asuhan Kebidanan Persalinan dan Bayi Baru lahir. Jakarta: Erlangga.

Maryati, dkk. (2010). Asuhan Kebidanan pada Kehamilan Fisiologis. Jakarta: Salemba Medika.

Notoatmodjo, S. (2011). Pendidikan dan Perilaku. Jakarta: PT Rineka Cipta.

Nursalam. (2008). Konsep-konsep Penerapan Metodologi Penelitian Ilmu Keperawatan : Pedoman Skripsi, Tesis dan Instrumen Penelitian Keperawatan. Jakarta: Salemba Medika.

Saifuddin, A. (2012). Buku Acuan Nasional Pelayanan Kesehatan Maternal dan Neonatal. Jakarta : Yayasan Bina Pustaka Sarwono Prawirohardjo.

Sarwono. (2008). Ilmu Kebidanan. Jakarta.Yayasan Bina Pustaka.

Simkin, P. (2007). Kehamilan, Melahirkan dan Bayi. Jakarta: PT Arkan.

Varney,H. dkk. (2008). Buku Ajar Asuhan Kebidanan.Jakarta:EGC.

WHO. (2009). Angka Kematian Ibu Menurut WHO.

http://www.antaranews.com diakses pada tanggal 15 Januari 2013. 
Wiknjosastro, H. (2002). Buku Ilmu Kebidanan. Jakarta :

Yayasan Bina Pustaka Sarwono

Prawirorahardjo. 